\title{
¿JUDICIALIZACIÓN DE LA EDUCACIÓN SUPERIOR?
}

\section{Introducción}

Una cuestión de creciente interés en los estudios de Derecho y Política es si los jueces toman decisiones políticas, y si está bien que lo hagan. Empíricamente esto parece ser una tendencia (Guarnieri y Pederzoli, 1999; Couso, 2004) debido especialmente a la expansión global de la justicia constitucional (que entrega a ciertos tribunales la facultad de revisar la constitucionalidad de las leyes y reglamentos ${ }^{2}$ ); aunque la importancia o influencia de las decisiones judiciales en el ámbito político trasciende dicho control.

Se habla de judicialización, en sentido amplio, cuando problemas que solían ser resueltos por órganos administrativos -en el contexto de políticas públicas- o en forma directa entre particulares (proveedores y contratantes de un servicio), pasan a ser resueltos principalmente en la sede judicial. Lo que ha ocurrido en Chile con los conflictos medioambientales ${ }^{3}$ es un ejemplo del primer tipo, en tanto que lo acaecido en el ámbito de la salud (con las alzas unilaterales

2 Así, Haas (2010) estima que el procedimiento de la Constitución en Alemania, que implica circunscribir normativamente la acción política, "deriva obligatoriamente en su judicialización".

3 Paradigma de esta especie es la Sentencia de la Corte Suprema (en adelante SCS) Rol $\mathrm{N}^{\circ}$ 1960-2012, de 28/08/2012, relativo al "Proyecto Puerto Castilla", acumulado con el Rol No 2703-2012 sobre "Proyecto Termoeléctrica Castilla". El fallo ha sido criticado como ejemplo de "activismo judicial", pues los jueces habrían buscando resolver "un problema general" antes que el caso concreto; erigiéndose en "experto técnico" y adoptando medidas que van más allá de la norma legal (Libertad y Desarrollo, 2012a y 2012b; García y Verdugo, 2013: 59-67). 
de los planes de las isapres ${ }^{4}$; o la responsabilidad médica ${ }^{5}$ ) constituye un ejemplo de lo segundo.

Dentro de sus causas se citan fenómenos de más largo alcance, como la constitucionalización de los derechos (Prieto, 2007); cambios en la sociedad, derivados de la mayor conciencia de las personas acerca de sus derechos, incluidos los derechos sociales y la difusión de los mecanismos para hacerlos exigibles ${ }^{6}$, así como el surgimiento de una concepción argumentativa del Derecho, que asigna a los jueces un rol mayor que el tradicional en la garantía de esos derechos ${ }^{7}$. Ciertamente, en nuestro caso la judicialización viene asociada a insuficiencias de las políticas públicas, a la ausencia o defectos de la regulación aplicable en un sector (que debería garantizar un derecho) y a una creciente actitud crítica respecto del funcionamiento de un servicio de interés público por parte de los usuarios del mismo o de la ciudadanía en general.

4 El leading case en este ámbito es la Sentencia del Tribunal Constitucional (en adelante STC) que declaró inconstitucional algunos numerales del Artículo 138 ter de la Ley de Isapres, Rol No 1.710-2010 de 06/08/2010 (antes, hubo fallo de inaplicabilidad, Rol № 976-2007, de 26/06/2008). Esta sentencia -junto con la STC Rol No 1.572 de 30 de octubre de 2010parece cuestionar la posibilidad del funcionamiento de mercados desregulados cuando se trata de derechos fundamentales, aunque Montt y Cárdenas (2011) no comparten este punto; y abre una vía para hacer justiciables otros derechos sociales (Coddou, 2010). El dato es que entre 2008 y 2012, los recursos de protección contra las alzas unilaterales en los planes de Isapres pasaron de 5.193 a 43.407. Cordero (2012) critica el fallo por su carácter regresivo y porque invoca un estándar (la reserva legal) que limita, precisamente, el desarrollo de los derechos sociales; García y Verdugo (2013) lo ponen, nuevamente, como un ejemplo de activismo judicial, en donde los jueces actúan como "reguladores" y "entregan respuestas maximalistas", "promoviendo con ello una industria del litigio".

5 Ya en el año 2003 se ingresaron en Tribunales más de 500 casos de responsabilidad médica (Pizarro, 2008). Hoy existe abundante jurisprudencia en diversas clases de problemas (De la Maza, et al., 2010; Delgado, 2009). Ahora, también se anuncia una nueva "ola" de judicialización a raíz de la promulgación de la Ley № 20.584, sobre derechos y deberes de los pacientes.

6 Epp (2013) sostiene que la democratización del acceso a la justicia no surge "desde arriba", por el liderazgo de jueces activistas, sino "desde abajo", debido a los movimientos de la sociedad civil, las organizaciones que se especializan en los derechos y las políticas públicas que financian agencias $\mathrm{u}$ organismos o aportan recursos para litigar a quienes carecen de ellos. Para la nueva concepción sobre los derechos sociales y su "justiciabilidad", ver Abramovich y Courtis (2004).

7 Aguiló (2008) señala que el auge de las teorías de la argumentación jurídica es debido, precisamente, a la evolución del constitucionalismo contemporáneo, que consiste en "dejar de interpretar los derechos y principios constitucionales como deberes cerrados que imponen (...) límites negativos a la acción política legítima; para pasar a verlos como el contenido propio de la acción política legítima" (p. 67). 
Si solo se tratara de un incremento de la competencia de los jueces -por encargo del legislador- y del número de litigios promovidos por los ciudadanos, este fenómeno solo sería objeto de estudios descriptivos. Sin embargo, algunos autores ven con preocupación la creciente influencia política de los tribunales, en cuanto a que pasarían a ser árbitros definitivos de lo que dispone la Constitución, sin limitarse estrictamente a lo que dicen las normas promulgadas; en otras palabras, lo que preocupa es la capacidad que tienen los jueces -a propósito de interpretar-de crear nuevas normas, sin ser órganos propiamente democráticos ${ }^{8}$.

Muchas veces la judicialización se usa como un sinónimo de activismo judicial. Como sugiere Hennig (2012), judicialización se refiere más bien al fenómeno amplio antes descrito; en tanto que activismo judicial sirve para denotar, en sentido restringido, una "postura proactiva del juzgador". Los críticos del activismo judicial, en efecto, cuestionan que los jueces puedan, en cualquier contexto, reconocer derechos o garantías implícitos ("no expresamente reconocidas por el derecho vigente"); o asignarles "un contenido más amplio que aquel consagrado positivamente" (Henríquez, 2010). En estos casos estaríamos en presencia de un activismo judicial en sentido fuerte; pero también habría un activismo judicial moderado cuando los tribunales, "destacando la importancia del derecho protegido, fallan en su favor en forma indirecta, protegiéndolo mediante la expansión del contenido de otros derechos fundamentales" (Henríquez, 2010 $)$. Es difícil, sin embargo, que pueda hablarse de activismo cuando los jueces son capaces de justificar sus decisiones echando mano a normas vigentes.

García y Verdugo (2013) proponen algunos criterios (luces de alerta) para detectar un juez activista:

8 Ely (1997) dice que el principal problema del control constitucional es que "un cuerpo que no es electo, ni es responsable de otra manera significativa, les está diciendo a los representantes elegidos por el pueblo que no pueden gobernar como lo desean" (p. 23).

9 Es curioso que, para esta autora, el activismo exige tanto la "intencionalidad del fallo" como "su manifestación expresa", ya que de otro modo estaríamos ante meros "avatares judiciales"; pero su trabajo no da cuenta de los criterios para evaluar esa "intencionalidad". 
- procura resolver los casos "aunque no tenga competencia"; privilegiando una argumentación sustantiva por sobre la procedimental y evitando las "doctrinas sobre deferencia a otros actores políticos" (tomadores de decisiones);

- "se desconocen las ataduras interpretativas" (los jueces se apartan del texto, la estructura y la historia de la norma que interpretan);

- pone menor énfasis en el "derecho objetivo conocido" y opera con más flexibilidad en la selección de fuentes;

- "tendencia a decisiones con amplios resultados" (maximalismo), entre otras.

Estos autores analizan la jurisprudencia sobre "tomas de establecimientos educacionales", no como ejemplo claro de activismo, sino como un área donde se dan algunos de sus elementos ${ }^{10}$.

Ninguno de nuestros críticos del activismo judicial considera los aportes de Dworkin sobre la relación entre derecho y política. Dworkin (2012) distingue dos concepciones del Estado de Derecho: la estatutaria, que entiende que los jueces deben limitarse a resolver sobre la base de decisiones adoptadas y promulgadas por el órgano político $^{11}$; y la otra es la concepción "centrada en los derechos". El derecho a que los tribunales velen por los derechos promulgados -dice Dworkin- es un mínimo indiscutible en una democracia. El estatuto (ley y decreto oficial) es fuente del derecho, pero no la única; también pueden serlo los principios, que son correctos y compatibles con los estatutos. Su herramienta práctica es la distinción entre argumentos de principios (basados en derechos) y "argumentos políticos" (o de política pública; fundados en alguna concepción del bienestar general o del interés público). La restricción adecuada es que los jueces deben fallar con argumentos de principios y no de políticas ${ }^{12}$.

10 El trabajo de García y Verdugo (2013) parte del análisis de un "voto de minoría" y en una serie no sistemática de fallos que cumplirían, más o menos, las "luces de alerta" que ellos proponen como modelo teórico. En materia de "tomas", dan por demostrada (en dos páginas) su ilicitud; critican los argumentos de propiedad, interés superior del niño, igualdad y debido proceso, así como las opiniones de algunos jueces acerca de las tomas como "cuestión política" (p. 68-80).

11 Las personas -según esta concepción- solo poseen los derechos que el Derecho les reconoce, con independencia de la justicia de la norma.

12 Dworkin cree que así los conflictos entre individuo y sociedad "se resolverán como cuestión de justicia” (p. 102); ya que en eso consiste el Derecho (y, por ende, la función de los jueces). 
Este estudio no pretende profundizar en la distinción teórica entre judicialización y activismo judicial, ni en torno a los límites de la interpretación legal, sino simplemente dar luces -desde la práctica jurídica- acerca del grado en que esos fenómenos podrían estar amenazando las políticas públicas en el ámbito de la educación superior. Para ello, partimos desde una explicación relativa al "derecho corporativo" de las instituciones de educación superior (IES) en referencia a los derechos de los estudiantes. Posteriormente analizamos el control judicial de los contratos educacionales y de la normativa interna de las IES que regulan las relaciones con sus estudiantes; primero por eventuales infracciones a la Ley de Derechos del Consumidor y, segundo, en sede de protección. Después, observamos algunas decisiones jurisdiccionales que, sin ser cuantitativamente importantes, han tenido relevancia pública, pues afectan a una gran cantidad de estudiantes o revelan prácticas de las IES que podrían ser contrarias al Derecho. Finalmente, evaluaremos cómo los jueces argumentan e interpretan su rol en estos casos -para determinar si reconocen ciertos límites a su potestad, dados por normas promulgadas o argumentos de principio, o si, como algunos reclaman, tienen una actitud expansiva, favorable a una mayor intervención en decisiones políticas- y avanzaremos algunas conclusiones respecto de los efectos que tal conducta judicial puede implicar para las políticas públicas en esta área. Quedan fuera del análisis los casos habituales o de normal ocurrencia, como las demandas laborales o civiles de cobro de dinero, que no son específicas del rubro educacional. La investigación incluye fallos dictados especialmente en los últimos cinco años.

\section{Consideraciones en torno al derecho corporativo de las Instituciones de Educación Superior (IES)}

La mayoría de nuestros autores incluye dentro de las fuentes formales del derecho chileno los actos jurídicos, en que las mismas personas dan lugar a normas que regulan sus relaciones. Estas normas son de carácter autónomo y particular, esto es, solo obligan a las partes que han concurrido a su otorgamiento (Squella, 2014). Esta potestad normativa de los particulares se sustenta en el principio del Artículo 1.545 del Código Civil: "Todo contrato legalmente celebrado es una ley 
para los contratantes". Las personas jurídicas cuentan con la facultad específica de regular su organización y funcionamiento interno ${ }^{13} \mathrm{y}$, además, suelen relacionarse con terceros (usuarios o clientes de sus servicios) mediante los llamados contratos de adhesión ${ }^{14}$. En ambos casos, a juicio personal, estamos en presencia de un método unilateral de creación de normas de tipo reglamentario; esto es, para los terceros que se relacionan con la persona jurídica, estas normas son aceptadas en bloque, sin que puedan intervenir en su otorgamiento.

Hernández (2002) observó que la carencia legislativa respecto de los derechos y deberes del estudiante entrega la regulación de esta materia a los reglamentos institucionales (y a los contratos), y el control de estos en manos de los tribunales. En ese momento, la vía principal -y casi exclusiva- para asegurar los derechos de los estudiantes y establecer límites a la potestad normativa de las IES era el recurso de protección (regulado en el Artículo 20 de la Constitución ${ }^{15}$ ).

La jurisprudencia desde temprano ha conocido este tipo de recursos, entendiendo que la potestad sancionatoria corporativa ${ }^{16}$ debe ajustarse a las garantías mínimas del debido proceso conforme al Artículo 19 No 3 de la Constitución (derecho a defensa; audiencia del afectado; imparcialidad del comité encargado de juzgar a los alumnos;

13 Esto se traduce, en el caso de las IES, en la libertad para fijar sus estatutos, con algunas menciones que exige la ley, y para dictar su reglamento interno, reglamentos de docencia y los que rigen la labor académica, etc. Estos son aprobados por la Asamblea de socios o Directorio, pero son obligatorios para todos los miembros de la entidad. La Ley orgánica de enseñanza reconoce la "autonomía" de las IES, entendida como "el derecho de cada establecimiento de educación superior a regirse por sí mismo, de conformidad con lo establecido en sus estatutos en todo lo concerniente al cumplimiento de sus finalidades" y comprende la autonomía académica, económica y administrativa (Artículo 104 de la Ley General de Educación, en adelante LEGE, contenido en el Decreto con Fuerza de Ley -DFL- No 2/2009 (del Ministerio de Educación) y publicada en el Diario Oficial con fecha 2/7/2010).

14 Aquel "cuyas cláusulas han sido propuestas unilateralmente por el proveedor sin que el consumidor, para celebrarlo, pueda alterar su contenido" (Artículo 16 de la Ley No 19.496). Sus características (López, 2010) son la generalidad (la oferta se dirige a una colectividad de contratantes eventuales); la permanencia y la minuciosidad (por lo detallada de la reglamentación).

15 El derecho a la educación mismo (Artículo $19 \mathrm{~N}^{\circ} 10$ ) no se encuentra protegido por esta acción constitucional, lo que da lugar a algunas de las críticas por "activismo judicial" respecto de la jurisprudencia que resuelve estos recursos, injustificadas según veremos.

16 Reconocida en el Artículo 554 del Código Civil: "Toda corporación tiene sobre sus miembros el derecho de policía correccional que sus estatutos le confieran". 
procedimiento, instancia y sanciones establecidas previamente en la reglamentación) y respetar el derecho de propiedad sobre la calidad de estudiante ${ }^{17}$.

El principal inconveniente de los contratos de adhesión es la posibilidad que ofrece de imponer cláusulas abusivas al adherente. Por ello, la Ley $\mathrm{N}^{\circ} 19.955^{18}$ modificó, entre otros, el Artículo $2^{\circ}$ de la Ley de Protección de Derechos del Consumidor (Ley $N^{\circ}$ 19.496) para hacer aplicables las disposiciones de esta ley a los contratos educacionales ${ }^{19}$. Esta ley establece normas de equidad para corregir los efectos de las cláusulas cuyo contenido no puede ser discutido y pactado libremente por las partes, dando lugar a la jurisprudencia que analizamos de inmediato en la siguiente sección.

17 La Corte Suprema (SCS Rol No 20.123-1992, de fecha 23/12/1992), en recurso de protección contra la Universidad de los Andes, confirmó un fallo de la Corte de Apelaciones -en adelante, SCA- de Santiago, que establece: "el hecho de quedar una alumna universitaria embarazada, siendo soltera, no puede considerarse como un acto inmoral"; al suspender por tal motivo a la alumna, "la universidad ha incurrido en un acto arbitrario, al pretender asilarse en su reglamento interno para encuadrar como un acto inmoral constitutivo de falta grave la conducta antes descrita"; y, "con dicho acto arbitrario, se ha afectado la garantía del Artículo 19 № 24 de la Constitución Política de la República, puesto que la calidad de estudiante universitario faculta al interesado para acceder a un título profesional cumpliendo las exigencias universitarias y legales establecidas al efecto, configurando una especie de propiedad sobre derechos incorporales" (Considerandos $6^{\circ}, 7^{\circ}$ y $8^{\circ}$ del fallo confirmado). En otro fallo (SCS, Rol No 2.295, de 10/05/2000), en recurso contra el Instituto Profesional (IP) Adventista, la Corte Suprema confirmó la SCA de Chillán, de 10/04/2000, sancionando que negar la toma de ramos a una alumna embarazada ya matriculada, "importa hacer una discriminación (...) que vulnera el derecho de igualdad ante la ley consagrado en el Artículo 19 № 2 de la Constitución Política de la República, desde que dicho estado o la lactancia materna, a juicio de los sentenciadores, no son impedimento para ingresar y permanecer en un establecimiento de educación superior"; ya que no puede estimarse que sea constitutiva "de un acto deshonesto, inmoral, inadecuado o falta deliberada o reiterada hacia cualquiera de los puntos contenidos en el Reglamento" (Considerandos $2^{\circ}$ y $3^{\circ}$ del fallo confirmado). Publicada en el Diario Oficial del 14/07/2004.

19 El texto del Artículo $2^{\circ}$ letra d) de esta ley solo hace aplicables a los contratos educacionales las normas de equidad y contratos de adhesión, información y publicidad (engañosa), incumplimiento y procedimiento judicial, excluyendo explícitamente las reclamaciones por la "calidad de la educación o por las condiciones académicas fijadas en los reglamentos académicos vigentes a la época del ingreso a la carrera o programa respectivo, los cuales no podrán ser alterados sustancialmente, en forma arbitraria". 


\section{Control judicial de infracciones a los derechos del consumidor}

Los contratos de prestación de servicios educacionales que las IES suscriben con sus alumnos son contratos de adhesión, con desequilibrio en el poder negociador de los contratantes, pues contienen cláusulas y condiciones generales impuestas por la institución a todos los alumnos que se inscriben masivamente en sus programas y carreras, que no pueden ser modificadas por el alumno (quien debe limitarse a aceptarlas o rechazarlas en bloque). Es también claro que existen importantes asimetrías de información entre las IES y los estudiantes que se matriculan en ellas, quienes no cuentan con información suficiente sobre las condiciones -en definitiva, la "calidad"- del programa al que ingresan y que, en la práctica, no dispondrán de elementos suficientes para verificarla del todo sino hasta egresar de la carrera. La educación es, al mismo tiempo, un derecho constitucional y una función social de la mayor relevancia, por lo que es de justicia y una exigencia del orden público educacional que este tipo de contratos, en su contenido y, sobre todo en su ejecución, cumplan con los principios y reglas de equidad que se derivan tanto de la Constitución como de la legislación, en especial la Ley No 19.496.

El Artículo 16 letra g) de esta ley señala la esencia de una cláusula abusiva, entendiendo por tales las que: "En contra de las exigencias de la buena fe, atendiendo para estos efectos a parámetros objetivos, causen en perjuicio del consumidor, un desequilibrio en los derechos y obligaciones que para las partes deriven del contrato"20. En este sentido, se ha dicho que los principios de buena fe y equilibrio en la relación jurídica deben entenderse como fuentes de integración (interpretación) del contenido del contrato, así como de los derechos y cargas de las partes (Sandoval, 2005).

20 Según el citado Artículo 16 de la Ley $N^{\circ} 19.496$, son casos de cláusulas abusivas aquellas que: faculten a una de las partes a dejar sin efecto, modificar o suspender unilateralmente el contrato (salvo que se concedan en beneficio del comprador); establezcan incrementos de precio no aceptados expresamente por el consumidor; pongan de cargo del consumidor los efectos de deficiencias, omisiones o errores administrativos; inviertan la carga de la prueba en perjuicio del consumidor; limiten en forma absoluta la responsabilidad del proveedor, privando al consumidor de su derecho de resarcimiento, y las que incluyan espacios en blancos. 
En un caso reciente y de relevancia pública el Servicio Nacional del Consumidor (Sernac) interpuso una demanda colectiva en contra de la Universidad del $\mathrm{Mar}^{21}$, denunciando:

- La existencia de cláusulas en los contratos educacionales donde la universidad se reserva la facultad de repactar unilateralmente o renegociar la deuda a su solo arbitrio en caso de atraso en el pago (sin el consentimiento del alumno);

- cláusulas en las que la institución se permite la modificación unilateral de las condiciones contratadas; por ejemplo: cerrar una carrera al no completar la cantidad mínima de alumnos, no abrir una carrera o un curso previamente contratado "por cualquier causa", cambiar arbitrariamente las mallas curriculares y la forma de prestar el servicio (que puede pasar de presencial a virtual) ${ }^{22}$;

- cláusulas que limitan la responsabilidad institucional (por ejemplo, en caso de accidentes dentro de sus instalaciones) y el derecho de los estudiantes a reclamar y exigir las indemnizaciones correspondientes; como ocurre cuando los alumnos renuncian a sus acciones civiles y a las devoluciones con los respectivos reajustes y/o intereses, aunque la entidad incumpla la prestación del servicio.

Este caso reviste interés, tanto por el próximo cierre definitivo de esta universidad y la reubicación pendiente de parte de sus alumnos, como porque obliga a los tribunales a pronunciarse frente a este tipo de prácticas. Respecto de varias de las alegaciones del Sernac existe algún precedente que muestra cómo han aplicado las reglas y los principios señalados nuestros Tribunales de Justicia. Veamos.

a) ¿Qué ocurre en caso de retiro o desistimiento del estudiante con posterioridad al plazo previsto para ejercer el derecho de retracto $^{23}$ ? En una ocasión, un padre demandó la devolución del dinero pagado por los servicios educacionales que estuvieron a disposición de la alumna, pero que finalmente no se prestaron. La

$2122^{\circ}$ Juzgado Civil de Viña del Mar; causa Rol No C-4802-2012.

22 Según el Sernac: "si bien una institución puede cambiar las mallas, las razones deben basarse en criterios objetivos que apunten a mejorar la calidad del servicio".

23 Plazo de 10 días contados desde la publicación de los resultados de admisión de las universidades del Consejo de Rectores, según lo prescrito en el Artículo 3 ter de la Ley $\mathrm{N}^{\circ} 19.496$ 
Corte de Apelaciones de Santiago falló en contra de la Universidad Andrés Bello (Unab) ${ }^{24}$, confirmando la sentencia de primera instancia. La Corte se cuestiona si, no obstante el servicio no se presta, "queda obligado el demandante al pago, porque así se pactó". En otros términos, el dilema es si el contrato debe regir "como una ley para las partes" o si, tratándose de un contrato de adhesión, la obligación de pago a todo evento, cuando no se presta el servicio, resulta abusiva, en tanto que desproporcionada (contraria al principio de equilibrio de las prestaciones y a la buena fe contractual). El fallo, en definitiva, ante "el hecho establecido que la educación de que se trata no se brindó ni se brindará", declaró nula la cláusula del contrato educacional que permitía el cobro y la retención completa, ordenando la devolución de los dineros y documentos correspondientes. Se funda en la necesidad de ponderar normas que pertenecen al sistema, pero que juegan en sentidos opuestos:

(...) en el ámbito de una legislación protectora para el contratante adherido: la defensa del consumidor persigue como propósito la búsqueda de un marco de equilibrio en las relaciones de consumo entre empresarios y consumidores o usuarios. Justamente el Derecho Público interviene con ello en un área reservada tradicionalmente a la regulación del Derecho Privado, porque la libertad contractual y la autonomía de la voluntad, como principios de derecho, deben conjugarse con otros principios como la buena fe, la igualdad ante la ley, y el equilibrio de las prestaciones.

b) ¿Qué pasa si al alumno solo le resta un ramo para titularse? La Corte de Apelaciones también falló en contra de la Unab ${ }^{25}$, considerando abusivas algunas cláusulas del contrato de prestación de servicios, que -junto con otorgar eximentes de responsabilidad a favor de la Unab- le permitían cobrar el 100\% del arancel anual a un alumno que se encontraba realizando un

24 SCA de Santiago, Rol No 2.335-2008, de 05/07/2008. Las citas corresponden a los considerandos $4^{\circ}, 9^{\circ}$ y $10^{\circ}$ de la SCA.

25 SCA de Santiago, Rol No 1.905-2011, de 14/05/2012. Confirma el fallo del $4^{\circ}$ Juzgado de Policía Local (en adelante JPL) de Santiago. La cita es del Considerando $2^{\circ}$ de la SCA. 
curso pendiente para la titulación ${ }^{26}$. El razonamiento basal es que ciertas cláusulas resultan abusivas, en tanto, una:

pone de cargo del consumidor los efectos de determinadas deficiencias $\mathrm{u}$ omisiones que no son claramente suyas $\mathrm{y}$, lo que es más importante, contiene limitaciones absolutas de responsabilidad que pueden privarlo de sus derechos -de orden público- por mala prestación de los servicios;

y otra:

atenta en contra de parámetros de buena fe objetiva -que es exigida por esa norma-, desde que con ellas se altera el equilibrio de las prestaciones, atendido lo exigente e inflexible de ese contenido y la clara desigualdad que existe en este caso entre proveedor y consumidor.

c) ¿Puede una IES modificar unilateralmente las condiciones en que ofrece el servicio? La Corte de Apelaciones ha resuelto que no, al confirmar una multa a la Universidad $\operatorname{Arcis}^{27}$ por cambiar unilateralmente las condiciones en que se imparte un magíster ofrecido inicialmente en modalidad semipresencial, a una alumna domiciliada en Arica. El fallo de primera instancia consideró que la cláusula del contrato que faculta a la universidad para modificar unilateralmente el plan de estudio por "razones académicas" infringe la Ley $\mathrm{N}^{\circ}$ 19.496, pues dicha expresión:

es de tal manera general y vaga, que prácticamente deja al arbitrio o razonamiento subjetivo (de) una persona el estimar que existen "razones académicas" (...), provocando un desequilibrio importante en los derechos y obligaciones de las partes del contrato de adhesión (Considerando $14^{\circ}$ ).

d) Por otro lado, cabe tener presente que la Corte de Apelaciones de Santiago rechazó la demanda y denuncia infraccional deducida por el Sernac en contra de la Universidad Pedro de Valdivia

26 El fallo, unánime, dispuso además que la universidad debía rebajar el arancel que se encontraba cobrando al alumno a un porcentaje del $20 \%$ de la matrícula, determinando que dicho porcentaje representa un punto de equilibrio al servicio prestado.

27 SCA de Santiago, Rol No 10.802-2009 de 4/1 1/2009. Confirma fallo del $4^{\circ}$ JPL de Santiago, Rol No 16.307-5-08 de 30/07/2009. 
$(\mathrm{UPV})^{28}$, relativa a la cláusula del reglamento de prestación de servicios que establece el quórum mínimo para que se imparta una determinada carrera, pues el reglamento -que se entiende forma parte del contrato- establece una obligación condicional, la que conforme al Artículo 1.567 Nº 9 del Código Civil, se extingue "por el evento de la condición resolutoria"29. Esa condición "no sería una cláusula abusiva", al no vulnerar la buena fe; dado que está "incluida en el contrato de prestación de servicios educacionales que libremente firmó la reclamante".

e) Por último, otro ítem que acumula reclamos de los estudiantes es el relativo a la publicidad engañosa ${ }^{30}$. En este rubro fue paradigmático el caso de la Universidad Tecnológica Metropolitana (Utem) y otras IES al ofrecer la carrera de Técnico en Ciencias Criminalísticas, en que la infracción al Artículo 28 letras b) y c) de la Ley $\mathrm{N}^{\circ} 19.496$ se produciría al haber promovido un campo ocupacional inexistente. La decisión de la justicia civil $^{31}$ fue favorable a la Utem, por entender que se informó de "convenios institucionales" sin haber garantizado el acceso o inserción laboral, "menos aún, si dicho plantel es de naturaleza estatal" (considerandos $63^{\circ}$ y $65^{\circ}$ del fallo). Pero tratándose de una IES privada sí existe un precedente condenatorio: así, en circunstancias similares a la anterior, la Corte de Apelaciones de

28 SCA de Santiago, Rol No 4192-2008, de 13/08/2008. Confirma fallo del JPL de Providencia, Rol No 8.215-2-2007. Citas de los considerandos $7^{\circ}$ y $8^{\circ}$ del fallo del JPL.

29 Es decir, al verificarse la condición (no cumplir el número mínimo de matriculados), se extingue la obligación.

30 El Artículo $1 \mathrm{~N}^{\circ} 4$ de la Ley $\mathrm{N}^{\circ} 19.496$ define la publicidad como "la comunicación que el proveedor dirige al público por cualquier medio idóneo al efecto, para informarlo y motivarlo a adquirir o contratar un bien o servicio, entendiéndose incorporadas al contrato las condiciones objetivas contenidas en la publicidad hasta el momento de celebrar el contrato". A su turno, el Artículo 28 de la misma ley dice: "Comete infracción a las disposiciones de esta ley el que, a sabiendas o debiendo saberlo y a través de cualquier tipo de mensaje publicitario induce a error o engaño respecto de: (...) b) La idoneidad del bien o servicio para los fines que se pretende satisfacer y que haya sido atribuida en forma explícita por el anunciante" y "c) Las características relevantes del bien o servicio destacadas por el anunciante".

31 Sentencia del $1^{\circ}$ Juzgado Civil de Santiago, causa Rol № 27.315-2007, de fecha 30/08/2013. Rechazó la querella infraccional y la demanda civil de indemnización de perjuicios; aún pendiente en Corte de Apelaciones. En este caso se entendió que la acción promovida no es exclusiva de un consumidor afectado, sino que corresponde también a un conjunto de alumnos; por lo que debe tramitarse como acción de interés colectivo. Ver SCA de Concepción, Rol No 738-2011, de 16/03/2012; y jurisprudencia de SCS en recursos de queja, en los roles $\mathrm{N}^{\text {os }} 2.084-2008$ y $5.752-2011$. 
Santiago confirmó el fallo que condena a la Universidad del Mar a una multa de 50 UTM y a pagar una indemnización por daño patrimonial -las sumas pagadas por matrícula y arancel-y moral a una alumna ${ }^{32}$, con base en que la publicidad efectuada respecto del campo laboral de la carrera de Perito Forense "indujo a error o engaño respecto de las características del bien o especial servicio ofrecido, en la especie, servicios educacionales respecto de una carrera profesional cuyo campo laboral es más limitado que lo publicitado" (Considerando $5^{\circ}$ del fallo de primera instancia).

Estos son los casos que han llegado a los Tribunales Superiores de Justicia. Tenemos constancia de otros casos de protección al consumidor en que solo hay fallo de primera instancia ${ }^{33}$ (con criterios similares a estos) y debe haber muchos que terminan por transacción, antes o durante el juicio. Es probable que conocida la jurisprudencia de los Tribunales, muchas IES han ido adecuando sus prácticas al estándar jurisprudencial. No se observan rasgos de judicialización, ni luces de alerta de un eventual activismo judicial, ya que los tribunales intervienen en el caso concreto y aplicando una ley vigente (con fallos a favor y en contra de las IES). Ni siquiera ha habido un aumento significativo de los litigios (cosa que se anunció al discutirse la modificación legal de 2004), si consideramos el creciente número de reclamos que el Sernac recibe ${ }^{34}$.

32 SCA de Santiago, Rol No 8.424-2009 de 14/08/2009. Confirma fallo del 27/04/2009 del $2^{\circ}$ JPL de Maipú. La SCS, Rol No 5.858-2009, de 1\%09/2009, rechazó en este caso el recurso de queja. Curiosamente, en otro caso análogo contra la Universidad del Mar, pero interpuesto por 39 denunciantes, la SCS, Rol No 9.417-2009, de 27/05/2010, acogió el recurso de queja declarando la incompetencia del JPL de Arica por las mismas razones aplicadas en el caso Utem.

33 Ver el informe "Aplicación de la Ley de protección de derechos del consumidor a la prestación de servicios de educación superior" del CNED que revisa 94 fallos de Tribunales de instancia, principalmente JPL de Santiago y Providencia, a partir de la publicación de la Ley $\mathrm{N}^{\circ}$ 19.955. Disponible en www.cned.cl

34 Entre enero y noviembre de 2013 se registraron 5.544 reclamos a IES, versus 4.348 en igual período 2012 (Fuente: Sernac, www.sernac.cl). Actualmente, Sernac realiza mediaciones colectivas con 23 IES a objeto de eliminar cláusulas abusivas detectadas en sus contratos. 


\section{Control judicial vía recurso de protección}

El control sobre los actos corporativos de las IES también puede darse por vía del recurso de protección, en la medida en que un estudiante sufra, por un acto arbitrario o ilegal, una lesión, perturbación o amenaza de alguno de los derechos enumerados en el Artículo 20 de la Constitución y sea necesaria la intervención (tutela) judicial urgente, para restablecer el imperio del Derecho.

Hemos agrupado la jurisprudencia de protección en cinco rubros:

- arbitrariedad en la aplicación de contratos o reglamentos;

- negativa en el otorgamiento de certificaciones y diplomas;

- ejercicio de la potestad sancionatoria;

- retención de la devolución de impuestos para el pago del crédito universitario; $y$

- sistema de admisión.

3.1. Respecto de la eventual arbitrariedad de los contratos o reglamentos

En este caso la Corte Suprema, acogiendo un recurso de protección contra la Universidad del Pacífico ${ }^{35}$, considera arbitraria (y, por ende, abusiva) la aplicación de una cláusula del contrato educacional que permite el cobro total del arancel anual en caso de retiro del estudiante cuando, en concreto, el retiro se debió a que la alumna padece una severa depresión, lo que es una situación de fuerza mayor (no voluntaria) y que había sido conocida por la universidad, acogiendo la solicitud de suspensión del respectivo período académico. De lo anterior se deriva no solo que la universidad ha ido contra sus propios actos, sino que su conducta resulta arbitraria y ha afectado la garantía constitucional del derecho de propiedad (Artículo 19 No 24 de la Constitución), "toda vez que dándose los supuestos para la no aplicación de la cláusula quinta del contrato se ha instado por la cobranza de una obligación que se encontraba suspendida”.

35 SCS Rol No 6007-2012, del 16/10/2012. Revoca SCA de Santiago de 20/07/2012. Cita del Considerando $7^{\circ}$. 
Por otro lado, rechazó un recurso presentado en contra de la Universidad San Sebastián (USS) ${ }^{36}$, que pretendía evitar el cobro de un semestre que la alumna estuvo impedida de cursar, por tener que cumplir con su actividad profesional de enfermera, producto del sismo acaecido el 27 de febrero de 2010. El fallo de primera instancia señalaba que la universidad, "entendiendo que ocurrió un evento de fuerza mayor aceptó las explicaciones de la estudiante y estuvo llana a condonar el $60 \%$ del arancel, congelándole además los estudios". La no aceptación por entero de estas razones se estimaba arbitraria por parte de la Corte de Apelaciones, porque al no prestarse el servicio educacional "la universidad no tiene un motivo causal bastante para mantener su pretensión de cobro del 40\% del arancel restante" (considerandos $5^{\circ}$ y $6^{\circ}$ ). La Corte Suprema, no obstante, estimó adecuado el voto de minoría del fallo, que reconoce la existencia de un contrato de matrícula; no siendo el recurso de protección la vía idónea para "derogar cláusulas contractuales que fueron legítimamente pactadas, librándose de todo el peso de la prueba que le corresponde en un juicio de lato conocimiento".

A su turno, la Corte Suprema confirmó el fallo que acoge un recurso contra la Universidad Mayor ${ }^{37}$, considerando arbitraria la decisión de no permitir a una alumna rendir en segunda oportunidad el examen de cierta asignatura "ya que no obedece a un concepto razonable ni explicado claramente y la inclusión de esa carrera dentro de la Facultad de Medicina puede inducir a error al estudiante interesado en postular a ella"; toda vez que el reglamento de la universidad reconoce a los "estudiantes de las carreras del área de la salud humana" el derecho a "rendir los exámenes de las asignaturas semestrales y anuales en dos oportunidades".

Más recientemente, la Corte Suprema revocó una decisión de la Corte de Apelaciones de Santiago, rechazando el recurso presentado por estudiantes adventistas por habérseles fijado pruebas

36 SCS Rol No 5481-2010 de 12/08/2010. Revoca la SCA de Concepción, Rol № 215-2010, de $12 / 07 / 2010$.

37 SCS, Rol No 2.565-2013, de fecha 02/05/2013. Confirma la SCA de Temuco de 10/04/2013, Rol No Protección-166-2013. La cita corresponde al Considerando $7^{\circ}$ del fallo apelado. 
los sábados ${ }^{38}$. El máximo Tribunal argumentó que el Reglamento de Docencia de Pregrado de la universidad (vigente a la fecha de ingreso de los recurrentes a la carrera) establece tal posibilidad y la obligación de los estudiantes de cumplir con el calendario académico. También señaló que el derecho a la libertad religiosa (Artículo 19 $\mathrm{N}^{\circ} 6$ de la Constitución) debe compatibilizarse con las situaciones académicas y contractuales que los actores asumieron libremente al elegir estudiar esa carrera en la USS. De consecuencia, el fallo descartó la ilegalidad o arbitrariedad, ya que la decisión "se ha adoptado en estricta aplicación de los reglamentos y programas académicos que rigen para la generalidad de sus alumnos".

\subsection{Respecto de los casos de negativa de las IES a entregar certificados, títulos o documentos por mora del alumno}

En este caso existen dos líneas jurisprudenciales que se revisan a continuación.

La primera, mayoritaria, califica de arbitraria la medida, no obstante que se encuentre establecida en los reglamentos internos o contratos de prestación de servicios. La arbitrariedad se funda en que constituye una forma de presión indebida a la luz de los principios generales del derecho y de las leyes; que, además, vulnera el derecho de propiedad de los estudiantes respecto de su calidad de tal o el derecho a la igualdad.

Así, la Corte Suprema confirmó la decisión que acoge un recurso de protección contra la Universidad Metropolitana de Ciencias de la Educación (Umce) ${ }^{39}$, por no entregar un certificado de título al encontrarse el estudiante en mora. Según el fallo confirmado, dicha conducta es arbitraria, pues "aparece desprovista de fundamento" en

38 SCS Rol No 1720-2014, de 11/03/2014. Revoca SCA de Santiago de 2/01/2014, Rol No 132.162-2013. En igual sentido, la SCS Rol No 8911-2013, de 30/12/2013, revocó la SCA de Antofagasta de 3/09/2013, en recurso presentado contra la Universidad de Antofagasta, por un alumno adventista que solicitaba tener por justificadas sus inasistencias a controles los sábados. En este caso el rechazo se fundamenta en que el reglamento de la universidad regula expresamente la situación y el alumno no siguió el procedimiento para acogerse a la excepción prevista en él. En ambos casos hay voto de minoría (por confirmar la SCA).

39 SCS, Rol N 6.647-2010, de 23/09/2010. Confirma la SCA de Santiago de 23/08/2010. Se citan los considerandos $4^{\circ}$ y $5^{\circ}$ de la SCA. 
cuanto la existencia de una deuda de arancel no sirve como tal, ya que "el ordenamiento jurídico contempla las acciones judiciales que la recurrida debe ejercer si pretende obtener el pago íntegro de su acreencia". Agrega que tal medida conculca la garantía de igualdad ante la ley (Artículo 19 № 2 de la Constitución):

(...) porque establece diferencias arbitrarias respecto de otros egresados de la misma casa de estudios superiores que se encuentran en una situación similar a la de la recurrente, esto es, en relación a aquellos a quienes se les permitió iniciar los trámites destinados a obtener su título profesional por haber cumplido con las exigencias académicas conducentes a ello.

El mismo argumento basado en la igualdad jurídica fue utilizado por la Corte Suprema para acoger un recurso contra la Universidad Adventista de Chile ${ }^{40}$, y otro contra la Universidad Mayor ${ }^{41}$, reiterando la arbitrariedad de la negativa a expedir la documentación que la alumna necesita para proseguir sus estudios en otro establecimiento ${ }^{42}$. En similar sentido, pero poniendo énfasis en la proscripción de la autotutela ilícita y en la conculcación del derecho de propiedad sobre la calidad de estudiante, se ubica el fallo de la Corte de Apelaciones de Santiago que acoge un recurso de protección contra la Universidad Santo Tomás (UST) ${ }^{43}$.

40 SCS, Rol N904-2010, de 4/02/2010. Revoca el fallo de primera instancia, que aplicaba el derecho corporativo de la entidad. Se trata de un estudiante al que, para rendir sus exámenes, se le exigió regularizar su deuda de arancel y al que se le negó la entrega de los programas de asignaturas, mientras no cancelare en efectivo el saldo documentado.

41 SCS Rol No 3.134-2008, de 08/09/2008. Confirma la SCA Temuco 27/05/2008. La universidad se negó a entregar un certificado "de no impedimento académico" a una alumna que fue eliminada por no matricularse para el período lectivo siguiente (ver, en especial, considerandos $1^{\circ}$ y $2^{\circ}$ de la SCA).

42 Cabe mencionar también la SCA de Santiago, Rol No 2.031-2010, de 9/07/2010, que condenó en costas a la Universidad del Desarrollo (UDD), aunque esta envió por correo certificado los documentos requeridos, antes del fallo, pues para obtenerlos fue necesario que la estudiante recurriera ante la Corte.

43 SCA de Santiago, Rol $N^{\circ} 1.584-07$, de fecha 4/05/2007. Coincide, en el año y la fundamentación, con la SCA de Concepción, Rol No 4.254-2006, de fecha 27/07/2007, que acoge el recurso de un exalumno de la Universidad de Concepción. Para las Cortes, el estudiante tiene un derecho de propiedad sobre un bien incorporal, constituido por su calidad de egresado del programa que cursó; y la solución unilateral del conflicto (autotutela ilícita) atenta contra el Artículo 76 de la Constitución, que entrega a los Tribunales de Justicia la facultad de conocer las causas civiles, de resolverlas y hacer ejecutar lo juzgado. 
$\mathrm{Al}$ acoger un recurso contra la USS ${ }^{44}$, las Cortes reiteran su doctrina de que resulta ilegítimo utilizar cualquier medio de presión distinto al legal, para obtener el pago de obligaciones del contrato que se estiman incumplidas, pero introducen un argumento adicional basado en la "doctrina de los actos propios", al expresar que: "la alumna obtuvo la calificación favorable de su tesis en el mes de julio de 2010 y luego aprobó su examen de grado, sin que en dichas oportunidades se haya reparado en su condición de morosidad". Esto lleva a estimar injustificada y, por lo tanto, arbitraria la medida, pues "con ello discrimina a la actora al privarla de la documentación que necesita y a la que otros exalumnos en su misma situación académica pueden acceder (...)".

La Corte de Apelaciones de Santiago introduce otro matiz relevante al acoger el recurso de protección en contra de la Universidad La República ${ }^{45}$, cuando señala que:

la educación universitaria es el objetivo primordial del contrato de educación que celebra la universidad con cada alumno, siendo el pago de la matrícula y la colegiatura anual la contraprestación de ese servicio, pero en ningún caso este último constituye la finalidad del contrato.

La universidad, al no brindar la educación a la cual estaba obligada contractualmente y negarse a restituir los documentos de pago y garantía a los padres y alumnos recurrentes, incurrió en actos ilegales y arbitrarios que vulneraron la garantía del derecho de propiedad (Artículo 19 No 24 de la Constitución), por cuanto les impide recuperar documentos que -al no recibir el servicioles pertenecen. Asimismo, el fallo entiende que "la universidad ha conculcado la libertad de enseñanza al impedir a los padres elegir libremente para sus hijos y a estos últimos por sí, una institución universitaria en que estos puedan proseguir sus estudios".

44 SCS Rol No 3.435-2011, de 19/05/2011. Confirma la SCA de Puerto Montt de 14/04/2011 Rol No 69-2011. Las citas corresponden a los considerandos $5^{\circ}$ y $6^{\circ}$ de la SCS.

45 SCA, Rol No 2.321-2008, de 17/10/2008. Se citan los considerandos $10^{\circ}, 11^{\circ}$ y $12^{\circ}$ del fallo. 
Más recientemente, revocando la SCA de Concepción y acogiendo los razonamientos del voto de minoría de dicho fallo, la Corte Suprema acogió un recurso de protección y ordenó a la Universidad del Biobío (UBB) tramitar el título profesional y entregar los certificados correspondientes de un estudiante que había cumplido los requisitos académicos para ello, a pesar de existir una deuda pendiente ${ }^{46}$. Del mismo modo, en otra decisión revocatoria, la Corte Suprema acoge un recurso en contra de la Universidad Arturo Prat sede San Pablo, y reconoce el derecho del estudiante a "dar comienzo al proceso de titulación en cuanto cumpla con todos los requisitos habilitantes para ello, con excepción de aquellos que se refieran a pagos o deudas pendientes para con la institución recurrida, sin perjuicio de hacerlas efectivas por otras vías"47. La cercanía de ambas sentencias, sumado al hecho de que acogen sendos recursos contra dos universidades estatales, podría indicarnos que esta es la doctrina vigente del máximo Tribunal.

La segunda de las líneas jurisprudenciales referidas a los casos de negativa de las IES a entregar documentos por mora del alumno (minoritaria) ha atribuido fuerza obligatoria a los reglamentos internos de las universidades, aplicando los principios generales de Derecho Civil de reciprocidad de actitud ante el incumplimiento ("la mora purga la mora") y de fuerza obligatoria de los contratos.

Así, en 2010 la Corte Suprema confirmó el fallo que rechazó un recurso de protección contra la Umce ${ }^{48}$ señalando el fallo confirmado que la universidad:

cuenta con un reglamento que regula el proceso de titulación, distinguiendo entre los aspectos administrativos, por así llamarlos, y los académicos; siendo una exigencia, en el ámbito del primero de ellos, no tener deudas con la universidad, exigencia que no se cumple en el caso de la recurrente, por

46 SCS Rol No 2530-2013 del 22/05/2013. Revoca la SCA de Concepción, Rol No 249-2013 de 9/04/2013. El Considerando $4^{\circ}$ del voto de minoría señala que el Reglamento de Títulos de la Universidad del Biobío "es ilegal por cuanto carece de razonabilidad y aparece contrario a los principios básicos del derecho que impiden la autotutela ilícita".

47 SCS Rol No 3019-2013, del 27/06/2013. Revoca SCA de fecha 3/04/2013.

48 SCS Rol No 1.696-2010, de 22/04/2010. Confirma SCA de Santiago de 29/01/2010, Rol No 988-2009. Se cita el Considerando $4^{\circ}$ de la SCA. 
lo que la universidad ha actuado dentro de sus facultades y de manera lógica y razonada al no entregar un certificado de título.

En 2009, la Corte Suprema también confirmó el fallo que rechazó un recurso de protección contra la Universidad de Valparaíso ${ }^{49}$, invocando esta vez la autonomía de los cuerpos intermedios (Artículo $1^{\circ}$ de la Constitución). En efecto, dice la SCA de Valparaíso que:

siendo la universidad un cuerpo intermedio capaz de darse su propia normativa, la que debe ser respetada tanto por el Estado como los propios miembros de dicha universidad, y habiéndose dado su propia reglamentación, que establece la obligación de encontrarse al día en los pagos para con la universidad, para iniciar cualquier actividad o expediente tendiente a la obtención del título o grado; a la universidad se le impide entregar un certificado de título, si la recurrente no ha cumplido con todas las exigencias que su propia universidad ha determinado.

La Corte Suprema en dos ocasiones, una en $2010^{50}$ y la otra en $2011^{51}$, revocó sendos fallos de la Corte de Apelaciones de Concepción, rechazando en definitiva dos recursos interpuestos contra la Universidad de Concepción, con exactamente el mismo argumento:

Cuarto: Que tratándose en la especie de un contrato de servicios educacionales, no aparece como ilegal exigir el cumplimiento de las obligaciones patrimoniales que este impone al alumno, tales como el pago de aranceles y de matrícula, a fin de recibir la contraprestación de parte de la institución educacional.

49 SCS No8.456-2009, de 3/12/2009. Confirma la SCA de Valparaíso de 2/1 1/09, Rol No 4172009. Las citas corresponden al Considerando $6^{\circ}$.

50 SCS Rol No 3.947-2010, de 22/07/2010. Es el caso de un alumno de magíster que quiere retomar sus estudios.

51 SCS Rol No 9.383-2011, de 23/11/2011. Se refiere a un alumno de Sociología que pretende continuar el proceso para obtener su título profesional. Este fallo tiene un voto de minoría, quien estuvo por confirmar la SCA, por las razones antes expuestas de la doctrina mayoritaria (proscripción de la autotutela ilícita y arbitrariedad porque se discrimina al actor al privarlo de obtener el título profesional pese a reunir los requisitos para ello, "en relación con los demás egresados que se encuentran en su misma situación académica”. 
Es llamativo que estajurisprudencia minoritaria, coincidentemente, ha favorecido en este período a las universidades tradicionales ${ }^{52}$, máxime cuando la doctrina mayoritaria y alguna jurisprudencia constitucional han señalado que la autonomía institucional es parte del contenido esencial de la libertad de enseñanza y favorece a las entidades privadas antes que a las estatales ${ }^{53}$.

\subsection{Respecto del ejercicio de la potestad sancionatoria}

La jurisprudencia relativa al ejercicio de la potestad sancionatoria de las IES por regla general tiende a aplicar la normativa interna; de modo que, cuando se ha seguido un procedimiento acorde a la normativa interna, las Cortes suelen rechazar los recursos de protección (salvo que la IES incurra en una arbitrariedad manifiesta).

Un caso reciente de connotación pública es el recurso interpuesto contra la Pontificia Universidad Católica de Chile (PUC) por un grupo de estudiantes sancionados por interrumpir -con diversas manifestaciones- la celebración del aniversario de los 20 años de la Fundación Jaime Guzmán, rechazado en definitiva por la Corte Suprema ${ }^{54}$. El argumento base es que la universidad, en uso de sus facultades estatutarias, inició un proceso de responsabilidad en mérito de conductas contrarias a sus "Principios" -aceptados por los estudiantes al inicio de sus carreras- y que "no se trata de revisar" por vía del recurso de protección,

52 Hay un puñado de casos anteriores al período de análisis (esto es, en otro contexto) que favorecen a universidades privadas. Así, la SCS, Rol No 1.776-2003, de fecha 03/06/2003, revocó la SCA de fecha 22/03/03, rechazando un recurso de protección contra la Universidad Bernardo O'Higgins (UBO), por existir una norma expresa del Reglamento General de Estudios, que se entiende conocida del recurrente (SCS Considerando $5^{\circ}$ ). En igual sentido, la SCS de fecha 30/10/2006, Rol N 5.198 - 2006, contra la Universidad de Viña del Mar.

53 No obstante, pensamos que la autonomía es nada más una garantía institucional de contenido estatutario, es decir, configurada por la ley, cuya naturaleza no es distinta para universidades privadas y estatales (León, 2011). El Tribunal Constitucional ha aplicado su doctrina de la autonomía universitaria a favor de la Universidad de Chile, admitiendo que ese principio tiene "intensidades diversas" según el caso (STC 2252-2012, c. 28 $8^{\circ}$. La STC 1892-11 no contradice esta conclusión, ya que se basa en una reforma constitucional y en la compatibilidad entre los principios de transparencia y autonomía.

54 SCS Rol No 3116-2013, de fecha 22/05/2013. Confirma la SCA Rol No 530-2013, de $02 / 04 / 2013$. La cita corresponde a los considerandos $4^{\circ}, 5^{\circ}$ y $8^{\circ}$ de la SCA 
las ponderaciones y conclusiones a que se arriba por el ente investigador, sino precisamente si existen las facultades al efecto y si se ha seguido una investigación acorde a la reglamentación respectiva; y, en este escenario, no se aprecian situaciones arbitrarias por el ente estudiantil recurrido, precisamente por haberse ajustado al procedimiento que prescribe el reglamento de la universidad y sobre la base de las evidencias recopiladas durante el curso de la investigación.

La misma doctrina sigue el fallo que rechazó el recurso de protección interpuesto por un alumno de la carrera de Derecho contra la Universidad Diego Portales (UDP) ${ }^{55}$, por estimar que las sanciones establecidas por la universidad cuentan con respaldo reglamentario interno, "lo cual confiere plena legitimidad a lo actuado por la universidad" y que en este procedimiento "no procede entrar al análisis de si el Comité de Ética tuvo fundamentos de hecho verdaderos, procedentes y plausibles para adoptar la resolución sancionatoria”. Lo que la Corte examina, en suma, es si la universidad ha procedido, con la debida audiencia del alumno, al estudio, ponderación y evaluación de su conducta estudiantil y de los antecedentes que él aporta, al tenor de sus propios estatutos y reglamentos.

No hemos detectado casos relativos a tomas de IES ${ }^{56}$. Las sentencias que examinan García y Verdugo (2013) se refieren a establecimientos de educación media; con todo, ellas no son ejemplos

55 SCS Rol No 1.846-2011, de 7/04/2011. Confirma SCA de Santiago, Rol № 6.908-2010, de 10/02/2011. Cita del Considerando $5^{\circ}$.

56 Solo pesquisamos un recurso de la Universidad de Concepción contra el Gobernador Provincial, para que Carabineros de Chile no realice conductas que pongan en riesgo la integridad física y psíquica de los estudiantes, y que al mismo tiempo causen daños a la propiedad universitaria. Según la Corte, que rechazó el recurso, "Carabineros de Chile tiene la obligación de actuar con el fin de resguardar el orden público y la seguridad de las personas" (Considerando $7^{\circ}$ ); si bien "el uso de la fuerza pública debe ser prudente, racional y proporcional” (C. 8º. Ver: SCA de Concepción de 29/09/2011 Rol No 1010-2011, ejecutoriada. 
de activismo judicial ${ }^{57}$. Como hemos visto, es usual que las Cortes esgriman la vulneración del derecho de propiedad, debido proceso o de la igualdad jurídica en los casos en que estima se han vulnerado derechos de los estudiantes. No hay un solo caso que vaya contra texto expreso de la Constitución y, como se observa en los casos anteriores, no hay una postura ideológica, ni siquiera garantista, de los jueces.

Cabe agregar que la Contraloría General de la República ha interpretado que, para las universidades estatales, es forzoso investigar y aplicar, si corresponde, medidas disciplinarias en caso de paralización de actividades (tanto para alumnos como para funcionarios que adhieran a ellas). También corresponde descontar remuneraciones a los funcionarios, por sus ausencias injustificadas, cuyo es el caso de la paralización ${ }^{58}$.

57 En efecto, la jurisprudencia reciente ha acogido diversos recursos de protección de estudiantes expulsados de sus establecimientos por haber participado en tomas o movilizaciones; así, SCA de San Miguel, de fecha 5/9/2011, Rol No 187-2011; SCA de San Miguel, de fecha 13/10/2011, Rol No 219/2011; SCA de Punta Arenas, de fecha 3/9/2011, Rol N 59-2011, y SCA de Valparaíso, de fecha 18/10/2011, Rol ํ508-2011. En todas ellas el razonamiento de la corte es deductivo (a partir de normas vigentes) y puede resumirse del siguiente modo: (A) si es el caso que por un acto arbitrario o ilegal se vulnera un derecho fundamental, entonces procede dar protección a ese derecho; (B) es el caso que un acto arbitrario vulnera un derecho fundamental, porque: no se ajusta al reglamento interno del establecimiento, o este no prevé un procedimiento contradictorio y afecta la "propiedad" sobre la calidad de estudiante, que es una cosa incorporal, o la igualdad ante la ley, o la garantía del debido proceso, al imponer arbitrariamente una sanción extrema; (C) procede dar protección al derecho afectado (y se acoge el recurso). Es cierto que en ocasiones hay "otras consideraciones" (obiter dicta); pero cuando una Corte dice que este es un problema "político" que debe ser resuelto por el Gobierno y no por los jueces (SCA de Valdivia, de fecha 18/10/2011, Rol No 421-2011) parece ser más bien un ejemplo de "autorrestricción" que de activismo.

58 Así, mediante Dictamen No 19973 de fecha 09/04/2012, la CGR señala que los académicos de la Universidad de Chile son empleados públicos, por lo que no pueden declararse en huelga y pesa sobre ellos el deber de atender necesidades públicas (en este caso la educación) en forma continua y permanente; por tanto, cabe descontar tales ausencias de sus remuneraciones -aplica Dictamen $N^{\circ} 62.446$ de 2009- sin perjuicio de las medidas disciplinarias que se establezcan. De igual forma, corresponde abrir una investigación sumaria respecto de los alumnos partícipes, asegurando siempre el derecho a defensa y debido proceso. Asimismo, el Dictamen No 75.894 de fecha 05/12/2011 declaró que es deber de las autoridades académicas adoptar las medidas para asegurar la continuidad y permanencia del servicio. 


\subsection{Respecto de la devolución de impuestos para el pago del crédito universitario}

También han llegado a sede de protección casos relacionados con la cobranza del crédito universitario (FSCU): unos (3.4.1), relativos a las atribuciones de la Tesorería General de la República para retener de la devolución de impuesto anual las deudas provenientes de créditos establecidos en la Ley $N^{\circ}$ 19.287; y los otros (3.4.2), sobre la facultad de las IES acreedoras para publicar los datos de los deudores en Dicom.

\subsubsection{Casos relativos a las atribuciones de la Tesorería General de} la República para retener la devolución de impuesto anual El Artículo $1^{\text {o }}$ de la Ley $N^{o} 19.989^{59}$ que modificó la Ley No 19.848 , sobre reprogramación de deudas a los FSCU, faculta a la Tesorería para:

retener de la devolución anual de impuestos a la renta que correspondiere a los deudores del crédito solidario universitario regulado por la Ley $\mathrm{N}^{\circ} 19.287$ y sus modificaciones, los montos de dicho crédito que se encontraren impagos según lo informado por la entidad acreedora, en la forma que establezca el reglamento, e imputar dicho monto al pago de la mencionada deuda ${ }^{60}$.

Las acciones judiciales presentadas tienen como argumento la vulneración del debido proceso (Artículo 19 N 3 de la Constitución) en cuanto se establece una comisión especial que impide, además, el derecho a defensa, en cuanto no se pueden alegar causales de extinción de la obligación y la garantía del derecho de propiedad, toda vez que se incurriría en un acto expropiatorio. La vía de protección se ha utilizado en este caso para hacer viable la acción de inaplicabilidad de las normas señaladas ante el Tribunal Constitucional.

59 Publicada en el Diario Oficial de 31 de diciembre de 2004.

60 Dicha facultad es análoga a la establecida por la Ley No 20.027, que establece el sistema de créditos para financiamiento de estudios de educación superior con aval estatal (CAE), cuyo Artículo 17 señala: "La Tesorería General de la República podrá retener de la devolución de impuestos a la renta que le correspondiese anualmente al deudor de crédito garantizado en conformidad a esta ley, los montos que se encontraren impagos según lo informado por la entidad crediticia acreedora en la forma que establezca el reglamento, e imputar dicho monto al pago de la mencionada deuda". 
El Tribunal Constitucional inicialmente declaró inaplicable por inconstitucional la norma antes referida ${ }^{61}$, argumentando del siguiente modo:

Tal forma de actuar de un servicio público no satisface, indudablemente, las exigencias mínimas de un racional y justo procedimiento, porque no permite a quien aparece como deudor de acuerdo con la información proporcionada por el Administrador del Fondo (...) ejercitar ni ante la Tesorería ni ante un tribunal de justicia otro medio de defensa que no sea la prueba del pago de la obligación y siempre que conste en un certificado emitido por el mismo ente cuya información es título suficiente para retener fondos de la devolución anual de impuestos. Una restricción tan drástica de los medios de defensa de una persona no tiene sustento racional, pues, aun cuando existen fundamentos objetivos para un cobro expedito de las deudas provenientes de los Fondos de Crédito Universitario, (...) ello no puede llegar hasta privar, en la práctica, de una defensa oportuna.

La suerte del recurso de protección en estos casos está atada a la declaración de inaplicabilidad, pues de no lograrse esta el acto no será ilegal, en cuanto tiene sustento jurídico expreso (mientras se ejerza en el modo establecido en la ley). Por ejemplo, la Corte de Apelaciones de Santiago ${ }^{62}$ ha resuelto que la Tesorería "no ha incurrido en acto ilegal o arbitrario al efectuar la retención de dineros que se impugna, de lo que resulta que no se ha vulnerado al recurrente su derecho de propiedad sobre los dineros objeto de la retención", rechazando un recurso de protección. En el mismo sentido, la Corte Suprema, recientemente, confirmó el rechazo del recurso de protección interpuesto en contra de la Universidad Católica del Norte, del Fondo Solidario de la misma y del Tesorero Regional de Antofagasta, fundado en que la retención de impuestos es una facultad prevista en la ley y que el recurso de protección no es vía para discutir la existencia de la obligación ${ }^{63}$.

61 STC Rol No 808-2007, de fecha 12/08/2008, unánime; la cita es del Considerando $11^{\circ}$. Luego, por mayoría, siguió declarando inaplicable el mismo precepto legal, en STC 1.393/2010; 1.411/2010; 1.429/2010; 1.437/2010; 1.438/2010; 1.449/2010; y 1.473/2010. 62 SCA de Santiago, Rol No 3.507-2008, de 25/11/2008. Cita de los Considerandos $7^{\circ}$ y $8^{\circ}$.

63 SCS, No 3980-2013 de 27/06/2013. Confirma la SCA de Antofagasta, de 14/05/2013. 
La doctrina del Tribunal Constitucional comenzó a variar en un caso en que, al haber empate de votos, se tuvo por rechazada la inaplicabilidad ${ }^{64}$, aduciendo el voto que resultó vencedor: "que la norma legal impugnada tiene por objeto establecer un sistema expedito de recuperación de una ayuda estatal" y que el deudor dispone de un plazo de 30 días para reclamar al administrador del fondo respectivo y oponerse así a la retención ante la Tesorería (considerandos $3^{\circ}$ y $4^{\circ}$ ). El fallo también aplica el deber de la comunidad de "contribuir al desarrollo y perfeccionamiento de la educación" (Artículo 19 $\mathrm{N}^{\circ} 10$, inciso $7^{\circ}$ ) en cuya virtud: "se establece un crédito especial del Estado que se otorga en condiciones privilegiadas y que, asimismo, tiene un régimen particular de cobro que lo adapta al cumplimiento de especiales fines de solidaridad (Considerando $7^{\circ}$ ). Se trata, según la nueva doctrina, de un sistema público de ayudas estudiantiles, que constituye un crédito especialísimo, con privilegios para el estudiante y prerrogativas especiales para el acreedor: "de la misma manera que la ley permitió a los beneficiarios del crédito acceder a condiciones mucho más favorables que las existentes en el mercado, la deuda que contrajeron se cobra por medios especiales" (Considerando $12^{\circ}$ ). Con la misma lógica del voto de minoría -agrega el fallo- no podrían publicarse deudas en el Boletín Comercial, o efectuarse los descuentos legales o pactados por parte del empleador, o los impuestos sujetos a retención. Finalmente, la STC 2.066/2012 $2^{65}$ modificó la doctrina previa a la STC $1.486 / 2010^{66}$, atendiendo a la dictación del reglamento de esta ley ${ }^{67}$ y a las circunstancias del caso. Argumenta que:

Se trata de un crédito "subvencionado", porque da varias garantías al deudor y se verifica que los estudios universitarios de la requirente fueron financiados por el Estado y que ella no ha pagado su crédito. Con ello, está rompiendo una cadena solidaria que busca beneficiar a otros, pues el fondo se constituye principalmente por las devoluciones que hacen los deudores. El fondo recauda sus créditos no para perjudicar

64 STC Rol No 1.486-2010, de 02/11/2010.

65 STC Rol No 2.066-2011, de 5/06/2012. Acordada por 5 votos contra 3. Citas corresponden a los Considerandos $11^{\circ}$ y $22^{\circ}$.

66 Los cambios de doctrina son legítimos si existen motivos y razones que lo justifiquen, los que deben explicitarse (STC Roles N ${ }^{\text {s }} 171-1993$ y 1.572-2010).

67 Decreto Supremo No 297, de Educación, publicado en el Diario Oficial de 19/11/2009. 
a nadie ni para obtener lucro, sino para volver a prestar esos dineros a otros estudiantes necesitados.

3.4.2. Facultad de las IES acreedoras para publicar los datos de los deudores en Dicom

La SCA de Concepción de fecha 4 de septiembre de 2008 rechazó un recurso interpuesto en contra de la Universidad de Concepción, por publicar en Dicom una deuda contraída entre los años 1983 y 1985 a pesar de que la ley no permite publicar morosidades transcurridos cinco años desde que la respectiva obligación se hizo exigible. El fallo establece que, existiendo una deuda vencida, la recurrida se encuentra legitimada para protestar el pagaré y disponer la publicación del protesto en Dicom, pues el Artículo $8^{\circ}$ de la Ley No 19.083 dispone que las nóminas de deudores morosos por las obligaciones allí señaladas, son públicas ${ }^{68}$.

\subsection{Respecto del sistema de admisión}

En el tema de admisión existen casos relativos a la admisión especial (3.5.1); a la PSU (3.5.2) y al ranking de notas (3.5.3). Los vemos en ese orden:

\subsubsection{Respecto de la admisión especial}

En este caso encontramos dos fallos que rechazaron sendos recursos de protección. El primero, contra la Universidad Austral ${ }^{69}$, considera que no hay arbitrariedad si se rechaza la postulación de una persona, por vía especial, fundándose en que su actividad laboral no está relacionada con el campo profesional de la carrera a la que intentaba

68 En similar sentido, la SCA de Chillán de fecha 02/06/2005, confirmada por SCS de 29/06/2005, Rol N².804-2005, que rechazó el recurso de protección contra la Universidad del Biobío, como continuadora legal del Instituto Profesional de Chillán, pues al protestar el pagaré e informar su morosidad a Dicom, no ha actuado ni ilegal ni arbitrariamente, atendido que el recurrente era deudor suyo. Por otra parte, "el Artículo 15 inciso $2^{\circ}$ de la Ley $\mathrm{N}^{\circ}$ 19.287, que establece normas sobre fondos solidarios de crédito universitario, señala que la nómina de los deudores morosos por las obligaciones a que se refiere esta ley, serán públicos y la Ley № 19.899 estableció que a dichas nóminas no le han sido ni le será aplicable lo establecido en la Ley N 19.812 sobre protección a la vida privada" (Considerandos $8^{\circ}$ y $9^{\circ}$ ).

69 SCS Rol No 3.250-2007 de 17/07/2007. Confirma SCA de Valdivia, de fecha 12/06/2007; los argumentos centrales están tomados de los Considerandos $5^{\circ}$ y $6^{\circ}$ de la SCA. 
ingresar; ni se vulnera la igualdad ante la ley si el postulante no acreditó que, en casos semejantes, como el de un trabajador con idéntica o similar experiencia laboral, haya habido aceptación de parte de la universidad. Es decir, se reconoce que la universidad, en uso de su autonomía, puede seleccionar a sus alumnos entre los postulantes que cumplan con los requisitos exigidos.

El segundo rechazó un recurso contra la Universidad Mayor ${ }^{70}$, de un estudiante que postuló a una carrera conforme el procedimiento y cumpliendo los requisitos dispuestos por la propia universidad, pero que al concurrir a materializar la inscripción y tras una prolongada espera, fue informado a viva voz que los cupos para la carrera se habían completado y que habría que aguardar por los resultados de la lista de espera. El fallo no advierte arbitrariedad en ese actuar, desde que no se verifica que no se han cumplido los requisitos de transparencia y objetividad que la LEGE establece en cuanto al proceso de selección de alumnos. En virtud de ello, tampoco ha podido vulnerarse el derecho constitucional de propiedad, desde que el recurrente solo ha tenido la calidad de postulante a la universidad, sin que la circunstancia de haber participado en el proceso de selección de la misma le otorgue más derechos de los que emanan de esa condición.

\subsubsection{Respecto de la PSU}

La PSU ha sido cuestionada por una alumna egresada de un liceo técnico profesional, quien presentó un recurso en contra del Consejo de Rectores (CRUCH), el Ministerio de Educación, la Universidad de Chile y las ocho universidades privadas adscritas a este sistema de admisión. El reclamo es que las cuatro pruebas de las que consta el instrumento se basan en los contenidos curriculares mínimos de la enseñanza científico humanista $(\mathrm{CH})$ y cubren materias que no están en el currículum de la educación técnico profesional (TP). Lo anterior deja a la recurrente y a todos los egresados de la educación TP en clara desventaja frente a los egresados de la $\mathrm{CH}$, con independencia de cuál haya sido su desempeño escolar, lo que lesiona el derecho de igualdad ante la ley. Lo anterior se agrava por el hecho de que cerca

70 SCA de Santiago, Rol No 1.683-2009, de 12 de marzo de 2010. 
del 65\% de los egresados de la educación TP pertenecen a los dos primeros quintiles de ingreso. A pesar de la justicia del reclamo ${ }^{71}$, la Corte de Apelaciones de Santiago declaró inadmisible el recurso de protección, porque los hechos "exceden las materias que deben ser conocidas por el presente recurso, atendida su naturaleza cautelar" 72 . El argumento de la Corte no es claro, pero notoriamente se trata de un caso de autorrestricción, en que la Corte evita pronunciarse sobre un tema de política pública, que tiene alcance general. El reclamo fue presentado posteriormente (en septiembre de 2012) a la Comisión Interamericana de Derechos Humanos, donde aún está pendiente.

\subsubsection{Respecto del ranking de notas}

Al cerrar este trabajo se rechazó un recurso de protección contra el aumento de ponderación del ranking de notas acordada por el CRUCH para la admisión 2014, la que -se alega- resultaría perjudicial para los alumnos de los llamados "liceos emblemáticos" (aquellos más selectivos dentro del sistema público). El fallo -otro ejemplo de autorrestricción- argumenta que las universidades persiguen un objetivo legítimo (implementar "instrumentos más equitativos y con mejor predicción sobre los resultados académicos de los postulantes"), con base en estudios técnicos, y que no afecta la igualdad ante la ley ${ }^{73}$.

\section{Control judicial por aplicación de la legislación general}

Tradicionalmente, como hemos visto, las IES y especialmente las universidades han sido consideradas como un grupo intermedio, con autonomía para la realización de sus fines específicos (Artículo $1^{\circ}$, inciso $3^{\circ}$, de la Constitución); tal autonomía les faculta para darse una organización y normativa interna, adecuadas a sus fines, y no tiene otras limitaciones que la moral, las buenas costumbres, el

${ }^{71}$ Mientras los estudiantes de la educación TP representan cerca del 45\% de la matrícula total; en 2011 solo un 10\% de los que rindieron la prueba logró entrar a las universidades adscritas al sistema único de admisión del CRUCH. Ver: "La PSU rinde examen" en Qué Pasa No 2174 de 07/12/2012, pp. 26-32.

72 SCA de Santiago, Rol No 491-2012, de 12 de enero de 2012.

73 SCS Rol No 15.493-2013 de 26/03/2014. Confirma la SCA de Santiago, Rol No 134.608 de $2 / 12 / 2013$ 
orden público y la seguridad nacional (Artículo 19 Nº 11 del Código Político $)^{74}$. Hasta ahora no se había reparado en que la noción de orden público, que implica la observancia de normas y principios básicos, sea para la convivencia o para la regulación de un determinado sector de la vida nacional, conlleva importantes restricciones a la autonomía y obliga a las IES a cumplir con la ley en todo sentido ${ }^{75}$. Las IES se rigen también por las normas de derecho común ${ }^{76}$ y pueden ser objeto de control judicial a este respecto. Más aún, el Ministerio de Educación puede revocar el reconocimiento oficial de una IES si contraviene el orden público (Artículos 64, 65, 74 y 81 de la LEGE).

De modo reciente han surgido casos de aplicación de normas generales respecto de universidades que si bien no masivas, podrían tener impacto en la política pública, a saber:

- querellas por delito de "otros engaños" (estafa) y apropiación indebida, en perjuicio de alumnos o trabajadores;

- eventual responsabilidad penal de personas jurídicas por actos de sus directivos (cohecho y lavado de activos);

- quiebra y nombramiento de un interventor judicial.

El caso paradigmático es la Universidad del Mar, pero esto puede alcanzar también a otras instituciones. Lo que se viene señalando es de tanta trascendencia, que tuvo una influencia decisiva en la decisión del Senado de fecha 17 de abril recién pasado, de aprobar por 20 votos contra 18 el capítulo III de la acusación constitucional contra el exministro de Educación Harald Beyer, declarándolo culpable de infringir la Constitución o las leyes, o de haber dejado estas sin ejecución (Artículo 52, número 2 letra b, de la Constitución) y destituyéndolo del cargo. El principal punto tiene que ver con el Artículo 53 de la LEGE, que señala que "Las universidades (...) serán siempre corporaciones de Derecho Privado, sin fines de

74 Por todas, véase la STC 523-2007. No nos hemos referido en este estudio al control de constitucionalidad de las leyes que corresponde al Tribunal Constitucional. Hay al menos tres fallos (STC) que contienen doctrina relevante: Rol № 352 del 15 de julio de 2002, Rol № 410 del 16 de abril de 2004 y la STC Rol № 523 de fecha 19 de junio de 2007.

75 Así lo establece expresamente el Artículo 58 de la LEGE, que permite negar el reconocimiento a una universidad "si los estatutos no se ajustaren a lo prescrito en la ley".

76 Según el Artículo 113 LEGE esto vale también para las universidades estatales. 
lucro para el efecto de tener reconocimiento oficial". La regla -que prohíbe a las universidades privadas perseguir fines de lucro- tiene consecuencias jurídicas y obliga al Ministerio de Educación a fiscalizar su cumplimiento. Pasamos, por tanto, a analizar estas otras "derivadas", en ese orden.

En materia penal, si los organizadores o directivos de una universidad establecen mecanismos para retirar excedentes en su propio beneficio, desviándolos del fin educacional (en perjuicio de los estudiantes de la misma), puede configurar la defraudación, el abuso de la confianza de terceros y la lesión patrimonial que conllevan los delitos de estafa y otros engaños, y la apropiación indebida.

Hay dos procesos en desarrollo cuyo desenlace nos interesa a estos efectos, en que los alumnos afectados se han querellado contra (ex) directivos de la Universidad del Mar y de la Utem. El primero se trata de una querella interpuesta en junio de 2012 por un grupo de 34 estudiantes de la Universidad del Mar, por el delito del Artículo 468 del Código Penal ${ }^{77}$. Argumentan que la universidad defraudó a su alumnado, haciéndoles creer falsamente que se trataba de una institución educacional sin fines de lucro, en circunstancias que "lo que había era una entidad de carácter comercial que en los hechos desarrolla una actividad de naturaleza mercantil", con el consecuente perjuicio al patrimonio y a los derechos de los alumnos. Dentro de los subterfugios utilizados por los dueños para obtener ganancias, los estudiantes denuncian: la "externalización artificial e injustificada en condiciones que exceden las habituales de mercado de una serie de servicios relevantes a empresas comerciales de propiedad de los directores y controladores de la universidad"; "la adquisición de activos fijos de la Universidad del Mar por empresas relacionadas"; "el arriendo de las sedes en que opera la Universidad del Mar a empresas comerciales del giro inmobiliaria cuya propiedad detentan por vía directa e indirecta, sus directores y controladores"; "la contratación de personas relacionadas directamente con los directores y controladores de la universidad" y la factorización de los pagarés, cheques y otros instrumentos de crédito suscritos por los alumnos. Entre otras

77 9 Juzgado de Garantía de Santiago, Causa RIT N5809-2012. 
obligaciones, la universidad habría dejado de cumplir con el pago de convenios para la realización de las prácticas profesionales (a pesar de que promociona sus carreras con esos campos clínicos), y el pago de las remuneraciones de los profesores ${ }^{78}$. A esto se suma la querella de los trabajadores de la universidad ${ }^{79}$ por el delito de apropiación indebida (Artículo $470 \mathrm{~N}^{\circ} 1$ del Código Penal), por las sumas de dinero descontadas de la remuneración para el pago de cotizaciones y otras prestaciones que no se efectuaron y por contrato simulado (Artículo $471 \mathrm{~N}^{\circ} 2$ del Código Penal).

El segundo de los procesos donde los estudiantes se han querellado se desarrolla según el procedimiento penal antiguo, con motivo de la querella presentada en contra del exrrector de la Utem por un grupo de 92 alumnos, por el delito de estafa y defraudación, ante el $34^{\circ}$ Juzgado del Crimen de Santiago. Se argumenta que los querellados ejecutaron actividades lucrativas, mediante la Sociedad Anónima Celta, con infracción del Estatuto de la Utem y en perjuicio de sus alumnos. Mediante dicha sociedad, que no tiene reconocimiento ni autorización para impartir docencia universitaria, se habría desarrollado la carrera profesional de Perito en Criminalística. El engaño y perjuicio patrimonial se habría dado al captar alumnos ofreciendo un campo laboral dado por el Ministerio Público y las Policías. Para que se acoja en sede penal esta interpretación hay mayores exigencias, obviamente, que para acreditar la infracción de publicidad engañosa prevista en la Ley $\mathrm{N}^{\circ} 19.496$ y el rechazo de esa acción (ya comentada) hace poco probable que se acoja la acción penal.

A su turno, el Consejo de Defensa del Estado (CDE) interpuso una querella por los delitos de cohecho, negociación incompatible y

78 Disponible en: http://ciperchile.cl/wp-content/uploads/00-QUERELLA-ESTAFAuniversidad-del-mar-vr-def.pdf

79 Juzgado de Garantía de La Serena, Causa RUC No $1110038915-2$. Los trabajadores señalan que su empleador: "creó sociedades inmobiliarias denominadas 'sociedad espejo', porque en ellas participan como socios las mismas personas naturales que son socios y directores de las universidades, con administración conjunta, con el mismo domicilio que la universidad, (...) y a través de esta se han retirado las utilidades de la Universidad del Mar, y puesto a su nombre sus activos, sus inmuebles, aumentando los gastos y pérdidas de la Universidad del Mar", todo ello en perjuicio de los trabajadores y alumnos de la universidad, pues la han dejado sin bienes para responder a sus obligaciones con ellos. 
lavado de activos $^{80}$, en contra del expresidente de la Comisión Nacional de Acreditación (CNA) y algunos exrrectores de universidades. En esta causa fueron formalizados el mencionado expresidente de la CNA, y los exrrectores de la Universidad del Mar; de la Universidad Pedro de Valdivia y de la Universidad SEK. También hay otras IES que están siendo investigadas. Todas estas acciones y la amplia difusión que han tenido en la prensa, han puesto en duda toda la institucionalidad del sistema de acreditación, motivando que el Gobierno presentase una iniciativa de ley para modificarla (Mensaje 498-360 del 8 de enero de 2013$)^{81}$.

La principal implicancia de esto es que se puede aplicar a las universidades la Ley de Responsabilidad Penal de Personas Jurídicas ${ }^{82}$; de hecho, el CDE amplió la querella y solicitó audiencia de formalización en contra de las personas jurídicas ya referidas, por medio de sus actuales administradores. Esto, de no mediar una solución legislativa (v.gr., creación de una Superintendencia de Educación Superior), presenta un potencial de judicialización,

$80 \quad 8^{\circ}$ Juzgado de Garantía de Santiago, Causa RUC 1200084351-0. Según la querella, estando en proceso de acreditación, la Universidad del Mar, por ejemplo, habría celebrado contratos con la Sociedad Gestión Ltda., de propiedad del expresidente de la CNA, por un total de $\$ 60.000 .000$, en razón de asesorías que no se habrían prestado.

81 A pesar de estar funcionando un "mercado" de agencias acreditadoras privadas, sujetas a la supervigilancia de una agencia estatal, la CNA, no encontramos jurisprudencia relativa a reclamos de las agencias, similar a la estudiada por Zapata (2007).

82 La regla general es que "la responsabilidad penal solo puede hacerse efectiva a las personas naturales. Por las personas jurídicas responden los que hayan intervenido en el acto punible, sin perjuicio de la responsabilidad civil que afecte a la corporación en cuyo nombre hubieren obrado" (Artículo 58 del Código Procesal Penal). Sin embargo, la Ley Nº 20.393, publicada en el Diario Oficial del 2/12/2009, consagra la responsabilidad penal de las personas jurídicas por delitos de lavado de activos, financiamiento del terrorismo y cohecho a un funcionario público. El Artículo 3 de la Ley No 20.393, dispone: "Las personas jurídicas serán responsables de los delitos señalados (...) $1^{\circ}$ que fueren cometidos directa e inmediatamente en su interés o para su provecho, por sus dueños, controladores, responsables, ejecutivos principales, representantes o quienes realicen actividades de administración y supervisión, siempre que la comisión del delito fuere consecuencia del incumplimiento, por parte de esta, de los deberes de dirección y supervisión. (...) Se considerará que los deberes de dirección y supervisión se han cumplido cuando, con anterioridad a la comisión del delito, la persona jurídica hubiere adoptado e implementado modelos de organización, administración y supervisión para prevenir delitos como el cometido (...). Las personas jurídicas no serán responsables en los casos que las personas naturales indicadas en los incisos anteriores, hubieren cometido el delito exclusivamente en ventaja propia o a favor de un tercero". Las sanciones aplicables son: disolución de la persona jurídica (en caso de delitos reiterados o de existir sanción anterior); prohibición de celebrar actos y contratos con organismos del Estado; pérdida parcial o total de beneficios fiscales y multa a beneficio fiscal. 
ya que son los jueces penales los llamados a decidir sanciones a las universidades acusadas de lucro, lo que inevitablemente tendrá incidencia en la política pública del sector.

En nuestra opinión, nada obstaculiza que las universidades privadas puedan ser objeto de una declaratoria de quiebra, toda vez que en la Ley de Quiebras no hay una norma que excluya a las corporaciones o fundaciones del procedimiento concursal. Así lo han entendido de forma casi unánime la jurisprudencia y la doctrina. En efecto, en el procedimiento de quiebra iniciado por el propio Instituto Chileno-Norteamericano de Cultura, corporación de Derecho Privado, la sentencia del $12^{\circ}$ Juzgado Civil de Santiago (SJC) que la declara en quiebra señala expresamente que se trata de un deudor civil, con lo que se cumplen los requisitos legales establecidos por el Artículo 42 de la Ley de Quiebras ${ }^{83}$. Lo mismo sostiene Puga (2004): "Las fundaciones, cooperativas y las corporaciones son personas jurídicas de Derecho Privado sin fines de lucro (...). Por lo mismo, sujetos de derechos y obligaciones. Por lo tanto, son susceptibles de ejecución colectiva".

Por ello, no es de extrañar que el $1^{\circ}$ Juzgado Civil de Viña del Mar, en marzo de 2013, declarara en quiebra a la Universidad del Mar, teniendo presente que "se encuentra en la situación contemplada en el punto 2 del Artículo 43 de la Ley de Quiebras No 18.175"84. Por otro lado, el $2^{\circ}$ Juzgado Civil de Viña del Mar, en enero de 2013, hizo lugar al nombramiento provisorio de interventor judicial en la

83 SJC de Santiago $\left(12^{\circ}\right)$, Rol $N^{\circ} 1.257-2012$, de 30/01/2012. La SCA de Santiago, Rol $\mathrm{N}^{\circ} 1.253-2002$ de 28/11/2002, por su parte, sobre declaración de quiebra del Club Social y Deportivo Colo Colo (Considerando $16^{\circ}$ ) sostiene: "su argumentación en el sentido que las Corporaciones no pueden ser declaradas en quiebra carece de asidero legal y doctrinario, atendido el texto expreso de la ley y la historia fidedigna de la misma, que permiten concluir que en nuestra legislación a diferencia de otros países no solo los comerciantes pueden ser declarados en quiebra".

84 SJC $\left(1^{\circ}\right)$ de Viña del Mar, Rol No 874-2013, de 15/03/2013. No obsta a esta conclusión que la SJC $\left(1^{\circ}\right)$ de Viña del Mar, de 16/04/2013, dando lugar a las incidencias de nulidad procesal promovidas por dos sociedades anónimas, una inmobiliaria y otra de inversiones, socios de la corporación universitaria, y por la Asociación Gremial de Académicos de la Universidad, dejara sin efecto la declaratoria de quiebra, y lo obrado desde la notificación de la demanda, por cuanto ella se funda en que quien se allanó a la demanda no tenía a la sazón la calidad de representante legal de la Universidad del Mar. 
causa Sernac con Universidad del Mar ${ }^{85}$. Si bien el interventor declinó el cargo luego de la designación de una síndico de quiebra, es un precedente que también vale la pena examinar por sus consecuencias en futuros casos problemáticos.

\section{Conclusiones}

La judicialización, en tanto mera descripción de un fenómeno social consistente en que nuevos derechos o nuevas dimensiones de la vida social que inciden en un derecho, que las personas estiman vulnerados -no solo por parte de los poderes públicos, sino también por organizaciones y empresas privadas que ejercen poder normativohacen que ellas recurran a la justicia para obtener protección y asegurar la equidad en la relación jurídica; no tiene nada de anómalo o negativo. Es, por el contrario, normal y sano para la democracia.

Los argumentos contra el activismo y la excesiva discrecionalidad judicial -y las tesis a favor del formalismo y la autorrestricción de los jueces, que esperan un razonamiento silogístico limitado a aplicar textos dotados de autoridad emanados de autoridades políticas y representativas de la voluntad ciudadana- son conceptualmente erróneas y, en el contexto chileno, ideológicamente conservadoras.

Es errónea en lo conceptual porque la aplicación de un texto envuelve siempre decisiones (la interpretación para determinar su sentido y alcance, la elección entre diferentes significados posibles, la ponderación con otras normas eventualmente aplicables, etc.) que, aunque son finalmente políticas, resultan inevitables. En efecto, los jueces no pueden excusarse cuando se reclama su intervención

85 SJC $\left(2^{\circ}\right)$ de Viña del Mar, Rol No C-4.802-2012, de 30/01/2013, cuaderno medida precautoria. El nombramiento de interventor es una medida precautoria, prevista en el Artículo 290 N $^{\circ} 2$ del Código de Procedimiento Civil (CPC), cuyo objeto es corregir la mala o incorrecta administración de una persona jurídica, cuando haya justo motivo de temer que se destruya o deteriore la cosa sobre que versa el juicio, o que los derechos del demandante puedan quedar burlados. Según el Artículo 294 del CPC: "Las facultades del interventor judicial se limitarán a llevar cuenta de las entradas y gastos de los bienes sujetos a intervención, pudiendo para el desempeño de este cargo imponerse de los libros, papeles y operaciones del demandado. Estará, además, el interventor obligado a dar al interesado o al Tribunal noticia de toda malversación o abuso que note en la administración de dichos bienes (...)". 
para dirimir una contienda ${ }^{86}$, y es peor para la democracia si a sus decisiones se las disfraza como actividad técnica o de mera operación lógica (esta sería la trampa del formalismo).

Es conservadora porque tiende a mantener el statu quo y exige fidelidad absoluta de los jueces con las intenciones del autor de la norma, es decir, con la ideología dominante al momento de dictarse las leyes. Pedirles a los ciudadanos que -para un ejercicio pleno de sus derechos- esperen pacientemente a que los órganos políticos, los únicos supuestamente democráticos, cambien la legislación es ingenuidad o, derechamente, mala fe (la trampa del neoliberalismo).

La judicialización (la inexcusable intervención judicial ante el reclamo de personas que sienten afectados sus derechos) suele ser mayor en ausencia de una ley que regule una materia ${ }^{87}$. Ello, a pesar de que el reclamo conservador (neoliberal) contra la regulación suele ser el riesgo de judicialización (nótese que este discurso se opone a la vez a la regulación legislativa y al activismo judicial).

Una legislación clara (y protectora de los derechos) más unos pocos casos paradigmáticos (de aplicación de la misma) pueden incentivar eficazmente la autorregulación y la adecuación de las prácticas institucionales (tendencia que se puede observar en la aplicación de la Ley de Protección de los Derechos del Consumidor a los contratos educacionales por parte de las IES).

De los casos analizados en este trabajo surge, como recomendación a las IES, la adopción de un sistema de reglamentos y contratos claros en sus contenidos, debidamente publicados y aceptados por los alumnos, cuyo contenido se ajuste al derecho (incluidos los criterios definidos por la jurisprudencia). Principalmente, las normas referidas a procedimientos disciplinarios y sanciones deben conformarse a los requisitos del debido proceso. Asimismo, la aplicación de las normativas y políticas dirigidas a los

86 Según los Artículos 76 de la Constitución y 10 del Código Orgánico de Tribunales.

87 Por ejemplo, como hemos detectado en este trabajo, han sido más numerosos los casos resueltos por las Cortes vía recurso de protección, que los casos resueltos por aplicación de la Ley del consumidor desde que ella incluyó a los contratos educacionales. 
estudiantes debe respetar los principios de proporcionalidad, buena fe e igualdad ${ }^{88}$.

Existe una tendencia expansiva de los derechos sociales en general y del derecho a la educación en particular; lo que inevitablemente ocurre a costa de otros derechos de libertad o de defensa (frente al Estado), como la autonomía de las IES y la libertad de enseñanza. Ello también resulta inevitable porque los derechos sociales reclaman una mayor intervención estatal. Esta expansión del derecho a la educación se desarrolla, a la par, por vía legislativa y jurisprudencial, dado que el derecho cambia por mecanismos tanto formales como no formales (por la interpretación). Pero, como se ha podido ver, la intervención de los jueces siempre es requerida por las personas -nunca actúan de oficio- y a partir de un texto vigente.

El contexto y los movimientos sociales tienen, indudablemente, efecto en la aplicación judicial de normas. Los jueces son miembros reflexivos- de la sociedad. Ello se puede observar en los casos relativos a las tomas de establecimientos (ya no se otorga automáticamente, como antes, el desalojo con auxilio de la fuerza pública, ni se convalidan las sanciones a estudiantes que participan en ellas); o también en la disposición más favorable de los jueces frente a las universidades estatales y tradicionales (casos de publicidad engañosa y retención de certificados). Pero en la medida en que hay razones normativas que justifiquen sus decisiones, no exceden sus atribuciones (no hay nada que reprochar). La crítica académica no puede fundarse simplemente en el desacuerdo con la decisión.

Ciertamente, la doctrina judicial puede llegar a tener un impacto importante en las políticas públicas (las reglas jurídicas son un componente esencial de las mismas); e, incluso, generar las condiciones para la reforma lega ${ }^{89}$. Pero eso no es motivo suficiente para enervar la decisión judicial cuando su intervención es requerida;

88 Establecer reglas claras es, si se quiere, una cara de la medalla; la otra será la forma -razonable- de aplicarlas a los estudiantes.

89 Así, el proyecto de ley sobre acreditación surge de la "derivada" penal descrita en este informe; del mismo modo que la reforma de la Ley de Isapres se hizo necesaria luego de los fallos del TC. 
tampoco es un elemento para configurar el activismo (es posible encontrar ejemplos de activismo judicial con alcances particulares, como el fallo de la Corte Suprema en el caso Atala ${ }^{90}$ ).

Lo que ocurre es que los redactores del texto constitucional (que no es lo mismo que el poder constituyente) concibieron los derechos subjetivos como límites a la intervención del Estado, incluso como una barrera infranqueable para el legislador (amparados en la tesis absoluta del contenido esencial de los derechos). Quisieron legitimar el orden positivo instaurado por la dictadura -con un marcado tinte neoliberal- y limitar el contenido de la legislación futura. Hoy, esos mismos derechos -que han evolucionado como lo hacen todos los textos positivos, gracias a su aplicación judicial y al cambio social-y otros incorporados por la legislación reciente comienzan a servir de base para un giro (una vuelta de tuerca) en el discurso jurídico, que gradualmente toma distancia del libre mercado y es proclive a limitar la excesiva autonomía de las empresas y corporaciones.

\section{Referencias}

\section{Libros}

Abramovich, V. y Courtis, C. (2004). Los derechos sociales como derechos exigibles. Madrid: Trotta.

De la Maza, I. (Comp.). (2010). Responsabilidad médica, Cuadernos de Análisis Jurídico. Santiago: Ediciones Universidad Diego Portales, Colección Derecho Privado, N VI.

Delgado, D. (2009). Valoración del daño moral en la responsabilidad médica. Santiago: Editorial Jurídica Aremi.

Dworkin, R. (2012). Una cuestión de principios. Buenos Aires: Siglo veintiuno editores.

Ely, J. H. (1997). Democracia y desconfianza. Colombia: Siglo del hombre editores.

Epp, Ch. (2013). La revolución de los derechos. Abogados, activistas y cortes supremas en perspectiva comparada. Buenos Aires: Siglo veintiuno editores.

90 SCS de 31/05/2004, Rol No 1.193-03. Ver comentario en: León (2011). 
García, J. y Verdugo, S. (2013). Activismo judicial en Chile ¿Hacia el gobierno de los jueces? Santiago: Ediciones LYD.

Guarnieri, C. y Pederzoli, P. (1999). Los jueces y la política. Poder Judicial y Democracia, Madrid: Taurus.

López, J. (2010). Los contratos. Parte general, Tomo I. Santiago: Legal Publishing.

Puga, J.E. (2004). El juicio de quiebras. Tomo I, Editorial Jurídica de Chile, Santiago.

Sandoval, R. (2005). Derechos del consumidor. Editorial Jurídica de Chile.

Squella, A. (2014). Introducción al Derecho. Santiago: Editorial Thomson Reuters.

\section{Capítulos de libro}

Aguiló, J. (2008). El método jurídico como argumentación jurídica. Sobre Derecho y argumentación (pp. 53-72). Palma de Mallorca: Leonardo Muntaner Editor.

Coddou, A. (2010). El nuevo Tribunal Constitucional y los derechos sociales: el caso de las Isapres. En J. Couso (Ed.), Anuario de Derecho Público 2010 (pp. 55-73). Santiago: Ediciones Universidad Diego Portales.

Cordero, L. (2012). Comentario a la sentencia de inconstitucionalidad de la tabla de factores de Isapres: un aparente triunfo de los derechos sociales. En Anuario de Derechos Humanos 2011. Santiago: Facultad de Derecho, Universidad de Chile.

Hernández, H. (2002). Estatuto jurídico del estudiante de educación superior. En A. Bernasconi (Ed.), La educación superior ante el Derecho (pp.105132). Santiago: Editorial Biblioteca Americana.

León, J.J. (2011). El conflicto de las universidades desde una perspectiva jurídica: lo público y lo privado en el debate sobre la autonomía universitaria. En Brunner, J.J. y Peña, C. (Eds.), El conflicto de las universidades: entre lo público y lo privado (pp.299-330). Santiago: Ediciones Universidad Diego Portales.

Montt, S. y Cárdenas, J. (2011). La declaración de inconstitucionalidad del Artículo 38 ter de la Ley de Isapres: mitos y realidades de un fallo histórico. En J. Couso (Ed.), Anuario de Derecho Público 2011 (pp. 1753). Santiago: Ediciones Universidad Diego Portales.

Pizarro, C. (2008). Responsabilidad profesional médica: diagnóstico y perspectivas. En AA.VV. Regímenes especiales de responsabilidad civil, Cuadernos de Análisis Jurídico (pp. 173-180). Santiago: Ediciones Universidad Diego Portales, Colección Derecho Privado, N IV. 
Prieto L. (2007). El constitucionalismo de los derechos. En M. Carbonell (ed.). Teoría del Neoconstitucionalismo. Ensayos escogidos (pp. 213-235). Madrid: Trotta.

\section{Artículos de publicaciones periódicas}

Couso, J. (2004). Consolidación democrática y Poder Judicial: los riesgos de la judicialización de la política. Revista de Ciencia Política, vol. XXIV, $N^{\circ} 2$, pp. 29-48.

Haas, E. (2010). TCF Federal: juridificación de la política - politización de la Justicia. Estudios Constitucionales, vol. 8, Nº1, pp. 367-378.

Hennig, M. (2012). La jurisdicción constitucional entre judicialización y activismo judicial: ¿Existe realmente "un activismo" o "el" activismo? Estudios Constitucionales, vol. 10, $N^{\circ} 2$, pp. 429-454.

Henríquez, M. (2010). Activismo judicial en la obtención de cobertura adicional para enfermedades catastróficas? Análisis jurisprudencial 2006-2009. Estudios Constitucionales, vol. 8, Nº1, pp. 401-424.

León, J. (2011). Justice, prejudice, and the basis for reasonable legal argument: the Karen Atala Case". COGENCY. Journal of Reasoning and Argumentation, vol. 3, No 2, pp. 125-145.

Zapata, G. (2007). Acreditación de la educación superior en Estados Unidos: el juicio de los Tribunales. Revista Calidad en la Educación, pp. 377-407.

\section{Otros}

Libertad y Desarrollo (2012 a). Activismo y accountability judicial. En Temas Públicos No 1.080 , septiembre 2012.

Libertad y Desarrollo (2012 b). Caso Castilla: cuando la justicia se transforma en regulador. En Fallos Públicos N²8, septiembre 2012.

Recibido: 24 /10/ 2013

Aceptado: 03 / 03/ 2014 